\title{
EL CONCEPTO DE PERSONA EN LA EDUCACION PERSONALIZADA
}

\author{
Jorge Mario Cabrera Valverde
}

\section{Introducción}

La idea de este artículo es dilucidar la concepción que, en la Educación Personalizada, se tiene respecto al término persona y respecto a la persona misma, cuyas implicaciones darán por resultado una sistematización que comprende tanto la individualización como la socialización educativas.

La Educación Personalizada no es producto de un solo autor; sin embargo, se debe al profesor Víctor García Hoz el que haya sido conocida internacionalmente y aceptada en numerosos países.

García Hoz nació en 1911 en la provincia de Burgos (España), en una población llamada Campillo de Aranda. Estudió en la Universidad de Madrid, obteniendo el Doctorado en Pedagogía. Fue Director del Instituto de Pedagogía San José de Calasanz, del Cónsejo Superior de Investigaciones Científicas (CSIC) y de la Revista Española de Pedagogía.

Formado en el tomismo y en la tradición católica, su llegada al profesorado permitió un cambio en la pedagogía practicada en España al introducir el método experimental y la estadística. Tal vez lo más renovador en él sea haber devuelto al hombre su coordenada espiritual. Mientras que la mayor parte de la Pedagogía moderna hace énfasis en la técnica educativa, García Hoz la centra en el hombre que lucha por superarse y por alcanzar su fin. Logra así, una visión unitaria y conjunta (García Hoz (d), 1970a) de los variados vectores que inciden en el ser humano para su propia formación y para dar formación a otros.

García Hoz es pionero de la Educación Personalizada en España. Cuando en 1970 publicó la primera edición de su libro Educación Personalizada, consiguió sistemati- zarla y extenderla por otros países. Un gran movimiento pedagógico surgió entonces en Italia, Francia, Portugal, Latinoamérica (Soto Badilla y Bernardini, 1981). Hoy se le considera el máximo representante de la Pedagogía Experimental en España (García Hoz, 1987).

Actualmente está preparando una colección de más de treinta volúmenes sobre la Educación Personalizada, de los cuales ya han salido a la luz varios, especialmente los que tienen que ver con la enseñanza formal.

Volviendo al tema de la persona, este término ha variado notablemente en su significación conceptual. Etimológicamente significa lo que suena. Proviene del verbo latino personare (resonar), el cual se aplicó a las máscaras usadas en el teatro clásico, que permitian aumentar la voz. Por el frente dichas máscaras reproducían la cara de un personaje; en la parte posterior tenian una peluca. El término griego correspondiente es prósopon (lo que está delante de la vista).

El buen actor representa su personaje identificándose con él de tal manera que no se confunde con otro. En la actualidad la palabra personalidad tiene también una acepción aplicada a una serie de características del individuo humano que lo hacen representativo de semejante individualidad. Hablamos entonces de alguien diciendo que tiene personalidad.

\section{La Educación. Panorámica conceptual en García Hoz}

García Hoz (1970) distinguirá entre varios significados de educación. En su significación vulgar la considerará "como una cualidad adquirida, en virtud de la cual un hombre está adaptado en sus modales externos a determinados usos sociales" (p.14). En esta acepción, 
diríamos que una persona educada es aquella que tiene buenos modales o que vive bien la urbanidad o que es muy cortés. El autor, sin embargo, procura profundizar en la significación etimológica de urbanidad haciéndola provenir de urbs, mientras que cortesía la relacionará con la Corte. Ambos orígenes etimológicos nos llevan a una cierta significación selectiva entre los seres humanos basada en el trato: la urbanidad en relación con aquel que vive en la ciudad y que tiene un contacto con muchos grupos sociales; el hombre de la Corte tendrá que aprender a tratar a muchas personas con las que se relacione, usualmente dentro de ciertos niveles sociales.

En resumen, la significación vulgar se refiere a los resultados que daría el haber aprendido ciertos convencionalismos sociales o formas de comportarse socialmente. Es algo adquirirdo por influencias externas. Su sentido no deja de ser algo superficial; pero, ihabra algo más interno en lo que se refiere a la palabra educación?

García Hoz (1970) pasa a ver su significación etimológica. Esta vez asigna al término educación dos significados: el primero como conducir (llevar a un hombre de un estado a otro, de una situación a otra), y el segundo como extraer (sacar de). El autor se inclinara. por esta segunda acepción del verbo educere (que dará al castellano educir̀), según la cual "la educación sería la acción de sacar algo de dentro del hombre" (p.15).

García Hoz no hace mención del otro verbo latino, educare que dio origen al educar castellano; pero encuentra en educere la respuesta a la educación como un proceso, un movimiento, que se refiere a lo interior del hombre y del cual vendrán todos los hábitos y formas de vivir que harán se diga del hombre que es educado en su primera acepción, o sea, la vulgar.

García Hoz (1970) tomará tanto una acepción como la otra combinándolas. Será un primer paso a la síntesis que hará de la educación como noción individualista y la educación como noción social. Pero, en ambas hay algo que le llama poderosamente la atención: la idea de perfección. Esta idea sera, para García Hoz, el concepto genérico en el cual apoyará la definición del proceso educativo.
A continuación, el autor purifica el sentido de esa perfección: ¿qué va a perfeccionar en el hombre la educación?; ¿su ser físico?, ¿su ser químico o tal vez el estético?, ¿su ser biológico, psíquico? García Hoz concluirá afirmando que es el perfeccionamiento de las funciones superiores del hombre, de las potencias específicamente humanas. Pero, hay algo más, lo que está detrás de todas esas facultades o potencias: una persona. La educación será ahora perfeccionamiento inmediato de las capacidades humanas y perfeccionamiento mediato de la persona humana.

García Hoz ve en la persona humana no una isla, sino algo que también necesita relacionarse: la educación es primariamente individual; luego, trasciende y se manifiesta social.

¿Qué es entonces el proceso educativo para García Hoz? Algo que se efectúa en una persona y es estimulado por otras. La educación se entenderá "como un proceso de asimilación cultural y moral y al mismo tiempo como un proceso de separación individual" (García Hoz, 1970, p.25).

¿Por qué es un proceso de asimilación? Porque los adultos actuarán sobre los jóvenes tratando de que estos últimos se incorporen al mundo de los primeros hasta identificarse con ellos. El educando obtendrá el idioma, las escalas de valores, las ideas científicas, los convencionalismos sociales, la moral, etc., predominantes en la comunidad en la que vive.

¿Por qué es un proceso de separación individual? Porque se trata de desarrollar en el sujeto sus posibilidades y, a la vez, disminuyendo sus limitaciones, permitir también que él mismo descubra las actividades y relaciones que van más de acuerdo con sus características propias.

Nuevamente, aparecen las manifestaciones de los objetivos que se pueden señalar a la educación: socialización e individualización. Pero, ¿pueden separarse? García Hoz opina que no: su separación daría origen a dicotomizar un proceso educativo que es único.

Ahora, el autor previene a los educadores para que no fuercen la situación de los educandos: el hombre tiene derecho a gobernar su propia existencia. Cada hombre tiene un carácter singular que debe ser respetado y comprendido. 
Con la educación personalizada, García Hoz (1981) intentará responder "al intento de estimular a un sujeto para que vaya perfeccionando su capacidad de dirigir su propia vida o, dicho de otro modo, desarrollar su capacidad de hacer efectiva la libertad personal, participando, con sus características peculiares, en la vida comunitaria" (pp.16 y 17).

García Hoz hace contrastar la posible homogeneidad de algunos grupos de alumnos con las diferencias subjetivas que hay en los mismos alumnos. "La educación -dirá- se realiza en cada sujeto de acuerdo con sus propias características" (1981, p.18). Un muchacho dentro de un grupo "homogéneo" estă capacitado para las instituciones normales; mas la educación perderá eficacia si no se toman en cuenta las diferencias personales en el desarrollo. De aquí el porqué de la educación personalizada.

\section{Fundamento antropológico-filosóficu de la Educación Personalizada}

\section{A Educación Individual, Educación Colectiva y Educación Personalizada}

Los términos educación individual, educación colectiva y educación personalizada tienen una evolución histórica aun cuando su significación inmediata se refiere a la relación numérica entre profesor y alumno.

Educación individual se aplicará al caso de la enseñanza dada a un solo alumno. Históricamente ha existido desde la antigüedad: la formación de príncipes o nobles, como en el caso de Alejandro Magno por parte de Aristóteles, es sólo un ejemplo de ella.

Al dejar de ser exclusivamente familiar, al entenderse como un derecho y una necesidad, la educación pasó a ser una actividad social que se da en instituciones escolares. Educación colectiva será esta última: el profesor lievará la educación de grupos de alumnos.

la educación individual subsiste actualmente en el caso de los profesores particulares, pero, el alumno queda privado de su fuente de desarrollo de vida social.

Aunque la educactón colectiva facilita el trato del alumno con sus semejantes, el profesor utiliza los mismos estímulos para todos, permitiendo sólo una reacción individual. En otras palabras, no se llega a considerar el proceso del aprendizaje en cada alumno.

En cambio, la enseñanza individualizada pretenderá reunir los dos métodos tratando de eliminar sus deficiencias. ¿Cómo intentará hacerlo? El profesor aplicará el método normal de enseñanza social, dará su clase, dejará tareas, comentará algún libro, etc., para después atender a los alumnos en el proceso mismo de su aprendizaje: cada alumno deberá poder encontrar en el profesor la ayuda necesaria y justa para que dicho proceso se lleve a cabo y se desarrolle eficazmente. No se trata de que cada uno haga individualmente o en grupo su trabajo, sino de que su actividad pueda ser orientada y dirigida de tal manera que no se detenga ni se obstaculice.

Estas ideas empezaron a ser sistematizadas a fines del siglo pasado y surgieron como reacción a la enseñanza colectiva tradicional y contra el pensamiento sociologista. Posteriormente, la educación individualizada fue ampliando sus miras hasta concebirse como una atención al individuo fortaleciendo interiormente a la persona para que sea más eficaz a la sociedad. Este concepto ampliado es el que ya se designa con el nombre de educación personalizada.

Para García Hoz (1981), el significado más profundo de esta educación está "en convertir el trabajo de aprendizaje en un elemento de formación personal a través de la elección de trabajos y la aceptación de responsabilidades por parte del escolar mismo" (p.22). El alumno tendrá así un estudio independiente en el sentido de que éste deberá ser responsable y autosuficiente.

\section{B. El sustrato: Ja persona humana. Manifestaciones de la Educación Personalizada}

¿En qué se apoya la educación personalizada para obtener sus conclusiones? En la noción de persona, o más bien, "en la consideración del ser humano como persona" (García Hoz, 1981, p.23). No, el hombre no es sólo un organismo que recibe estímulos y reacciona ante ellos, sino -principalmente- un ser activo, investigador, que cambia el mundo. 
La educación personalizada se convierte en tal cuando singulariza a la persona a la que se dirige: un sujeto determinado con características propias, que se siente comprometido a responder (responsable) de sus posiblidades personales y que, al vivir y actuar como persona, se ennoblece. El concepto de "persona" en García Hoz es de connotación dinámica: el hombre es "persona", sí, pero debe perfeccionarse, debe proyectarse hacia el futuro para plenificar su ser personal.

García Hoz encontrará tres notas en este concepto de persona de las cuales obtendrá las orientaciones fundamentales de la educación personalizada. Estas notas podrían llamarse también:

\section{Elementos personales que fundamentan la educación personalizada}

El primero de estos elementos o notas es:

\section{La singularidad}

Esta nota esencial hace que cada persona sea numéricamente distinta de cualquier otra e, incluso, cualitativamente distinta, lo cual la hará constituirse de un modo determinado.

Garcia Hoz (1981) modificará la concepción de educación integral al afirmar que la educación personalizada se presenta como educación integral entendida "como enriquecimiento y unificación del ser y la vida humana" (p.24).

El sujeto deberá conocer sus posibilidades y limitaciones, tanto cuantitativa como cualitativamente, y poderlas proyectar al mundo fuera de sí mismo. Para hacerlo requerirá de orientación, y el manifestar su singularidad llevará a la originalidad (cualidad que permite considerar a alguien origen de algo). García Hoz terminará haciendo casi una sinonimia entre originalidad y creatividad. El hombre será capaz de progresar gracias a su creatividad y por ello esta característica se convierte en un punto clave a ser desarrollado por la educación personalizada: crear es sólo atribuible a una persona, a toda persona, aun cuando dicha propiedad esté en unas personas en mayor grado que en otras.
Unos años atrás, García Hoz (1970, p.27) había utilizado la palabra dignidad en vez de singularidad, afirmando que en virtud de la dignidad, el hombre se siente sujeto, "realidad distinta y superior al mundo de puros objetos que le rodea". Ahora, la incorpora a:

\section{Ia autonomia}

El hombre se siente y se considera autonomo, principio de sus propias acciones, capaz de gobernarse a sí mismo.

El desarrollo y perfeccionamiento de estas ideas en García Hoz, le hará decir que la dignidad proviene de esta autonomía. Además, el hombre es superior a los objetos, el hombre los domina. Su dominio se manifiesta de dos maneras: conociendo y actuando sobre ellos.

Al conocer, el hombre domina las cosas porque posee algo real del objeto conocido: en su mente está la idea del objeto. En la medida en que un objeto es "mirado" o "conocido" se sentirá como una cosa, como si le quitaran algo de su realidad.

Por la acción el hombre modifica las cosas según ideas preconcebidas y su dominio es más claro.

De estas dos formas de dominar, García Hoz dirá que se derivan el mundo de la cultura y el mundo de la técnica. Cuando un sujeto se incorpora a ellos se desarrolla como persona.

La autonomía como capacidad de gobierno de sí mismo lleva directamente a la libertad, de cuyo concepto García Hoz distinguira "la libertad de" y "la libertad para". La primera será ausencia de coacción y vendrá a ser independencia. La segunda tiene una connotación positiva de capacidad, de eleccion. Ambas son necesarias para entender el concepto de libertad: independencia como condición, y elección como una acción fecunda.

Aparece entonces otro objetivo de la educación personalizada: educar para elegir bien, para elegir correctamente aun cuando dentro de dicha elección tiene que incluirse la capacidad de aceptación o de rechazo.

Si las posibilidades de elección son futuras, la libertad se especificará como libertad de iniciativa. 


\section{La apertura}

En cuanto individuo, el hombre es absolutamente incomunicable en el ser, pero su persona tiene necesidad existencial de abrirse a otros seres. El hombre se encuentra con una serie de relaciones impuestas por otros sujetos con los que tiene que convivir. La educación personalizada tomará también este campo como objetivo suyo siendo dividido en cuatro partes: relaciones familiares, relaciones de amistad, relaciones sociales y relaciones con Dios. Estas últimas relaciones han sido tocadas ampliamente en sus obras La tarea profunda de educar y Pedagogía de la lucha ascética.

García Hoz asegura que toda relación humana es comunicación que requiere una capacidad expresiva y comprensiva por parte del sujeto comunicante.

\section{Trascendencia de la Educación Personalizada}

Ante el panorama tan cambiante de la sociedad y de la misma educación, García Hoz concluía en 1970 diciendo "que la educación de hoy tiene como tarea propia la de preparar hombres que sepan trabajar, pero que sean capaces de trascender al trabajo mismo para encontrar en él su profunda significación humana, hombres capaces de vivir en comunidad sin convertirse en masa, de participar en la vida y en los problemas de la sociedad de hoy de acuerdo con su propio criterio y haciendo uso de su responsable libertad personal. Y junto a la vida social y de trabajo, la educación tendrá también que desarrollar y fortalecer la capacidad del hombre para su vida de amistad y de familia en un mundo en el que los grupos pequeños tienen cada vez menos fuerzas, y para su vida de fe en un mundo secularizado" (1970, p.32).

Pam García Hoz, la educación personalizada viene a resolver tres preocupaciones fundamentales en la educación de hoy: la eficacia de la enseñanza, la democratización de la sociedad y de las instituciones escolares y la especial atención de la dignidad humana, pero, más que por sus consecuencias en esos tres planos, lo importante es su origen: "la consideración del hombre como persona, su carácter de sujeto activo frente a un mundo de realidades objetivas, respecto del cual ocupe un plano de superior dignidad y cuya vida es plenamente humana, auténtica, solo mediante el ejercicio de su libertad" (García Hoz, 1981, p.36).

La libertad, para García Hoz, será un tema que desarrollaráen otras ocasiones, ampliándolo o profundizándolo. En la educación personalizada será de capital importancia, pues deberá llevar al educando a ejercitarse en el uso de la libertad, debe presentar al alumno posibilidades de elección de tal manera que su decisión surja como consecuencia de la reflexión o ponderación y conocimiento de las distintas posibilidades y, una vez elegida alguna, a aceptarla con todas sus consecuencias. Para ello debe contar con actividades y personas que lo orienten y vaya aprendiendo a decidir, a trabajar, a comunicarse, a convivir y -ipor qué no?- a influir o colaborar (participar) en el gobierno de la misma institución escolar a la que asiste.

Dos de los cambios a que lleva la educación personalizada se refieren no tanto a la sociedad o a sus integrantes, sino a la manera de enfocarlos: La sociedad es cambiante y las modificaciones que experimenta (técnicas, económicas, etc.), son cada vez más rápidas y constantes. No tendría sentido educar a las personas para una sociedad de características determinadas sino precisamente para una cambiante.

El otro cambio se refiere al sujeto: no serviría de gran cosa enseñar a los alumnos a resolver este o aquel problema, sino más bien capacitarlos y darles criterio para conocer cada situación y saber cómo deben reaccionar adecuadamente frente 2 ellas: lo importante será hacerles desarrollar hábitos de trabajo y criterios para saber elegir; debe saber "distinguir lo importante de lo trivial, lo permanente de lo transitorio, lo real de lo aparente" (García Hoz, 1981, p.41), poder determinar el tipo de vida que le sea más conveniente. En otras palabras, la educación deberá entenderse como un proceso de ayuda -basado en el trabajo y en la personal libertad responsable de cada alumnoque tiene como fin capacitarlo para elaborar y llevar a cabo su proyecto propio y personal de vida. 